\section{Quality of life in patients with seborrhoeic dermatitis in KwaZulu- Natal, South Africa}

To the Editor: Skin diseases may have a severe effect on the quality of life (QOL) of affected individuals, ${ }^{[1,2]}$ but their impact has rarely been investigated in the developing world. In South Africa, there have been no studies conducted on patients with seborrhoeic dermatitis (SD). A cross-sectional study was undertaken in the ILembe District, KwaZulu-Natal Province, assessing the QOL of patients presenting with SD, correlating clinical severity and demographic parameters.

Forty-five consenting participants, with a clinical diagnosis of $\mathrm{SD}$, were invited to participate. QOL was assessed using the Dermatology Life Quality Index (DLQI). ${ }^{[3]}$ The severity of the condition was assessed by a dermatologist and graded at individual sites for erythema, thickness, scaling and pruritus on a three-point scale. Body surface area involvement was calculated using the rule of nines and the sites of involvement were recorded.

A detailed demographic profile was completed for each patient (Table 1). The median severity score was 24 and the median DLQI score was 17, which equates to a very large effect on the QOL. ${ }^{[3]}$ The QOL varied depending on sex, educational level, ethnic origin, home language, marital status, residence, HIV status and site of involvement. Female patients were more negatively influenced by the disease, confirming the findings in three other studies. ${ }^{[4-6]}$ Patients with no formal schooling were more adversely affected. The way the questions were interpreted and the perception of disability may explain the differences in DLQI between the groups. Visible body areas and groin involvement had a greater impact on a patient's QOL. As appearance plays an important role in
Table 1. Demographic profile of study sample and DLQI scores $(N=45)$

\begin{tabular}{|c|c|c|}
\hline & $n(\%)$ & DLQI \\
\hline Mean age (years) & 37 & \\
\hline \multicolumn{3}{|l|}{ Sex } \\
\hline Male & $19(42.2)$ & 11 \\
\hline Female & $26(57.8)$ & 17.5 \\
\hline \multicolumn{3}{|l|}{ Ethnic origin } \\
\hline Black & 40 (88.9) & 17 \\
\hline Asian & $3(6.7)$ & 10 \\
\hline White & $2(4.4)$ & 4.5 \\
\hline \multicolumn{3}{|l|}{ Marital status } \\
\hline Single & $31(68.9)$ & 17 \\
\hline Married & $4(8.9)$ & 13 \\
\hline Divorced & $1(2.2)$ & 6 \\
\hline Widowed & $2(4.4)$ & 9.5 \\
\hline Living together & $7(15.6)$ & 18 \\
\hline \multicolumn{3}{|l|}{ Home language } \\
\hline isiZulu & $39(86.7)$ & 17 \\
\hline English & $6(13.3)$ & 8 \\
\hline \multicolumn{3}{|l|}{ Residence } \\
\hline Urban & $34(75.6)$ & 17 \\
\hline Rural & $9(20.0)$ & 19 \\
\hline \multicolumn{3}{|l|}{ Level of education } \\
\hline Primary & $9(20.0)$ & 17 \\
\hline Secondary & $27(60.0)$ & 17 \\
\hline Tertiary & $4(8.9)$ & 19.5 \\
\hline No schooling & $5(11.1)$ & 22 \\
\hline
\end{tabular}

our society, patients felt more embarrassed and self-conscious. In addition groin involvement may affect intimacy with a partner.

SD has a higher prevalence in patients with HIV and has been found in up to $40 \%$ of seropositive patients, ${ }^{[7]}$ notably, HIVpositive patients ( $n=37,82.2 \%$ ), with a CD4 count $<350$ cells $/ \mathrm{mm}^{3}(n=19,51.4 \%)$, and patients who had been on antiretrovirals (ARVs) for $>1$ year $(n=13,46.6 \%)$ had higher DLQI and severity scores. Although the introduction of ARVs has reduced the number of opportunistic dermatological conditions seen, there has been no change in the prevalence of primary HIV-related inflammatory diseases. ${ }^{[7]}$ This is illustrated by a lack of significant associations between HIV-positive patients on ARVs v. those who were not on ARVS and QOL (on ARVs $n=29$, median 18; not on ARVs $n=8$, median 17).

This study highlights that QOL tools are valuable in understanding the impact of skin disorders and will help in providing holistic, comprehensive management, offering a patient's own perspective of their debilitating skin condition.

\section{Nerissa Moodley}

Dermatology Medical Officer, Stanger Regional Hospital, KwaZulu-Natal, South Africa nerissazn@yahoo.com

Koraisha Hoosen, Ncoza Cordelia Dlova

Department of Dermatology, King Edward VIII Hospital, Durban, KwaZulu-Natal, South Africa

1. Harlow D, Poyner T, Finlay AY, Dykes PJ. Impaired quality of life of adults with skin disease in primary care. Br J Dermato 2000;143(5):979-982. DOI:10.1046/j.1365-2133.2000.03830

2. Jobanputra R, Bachmann M. The effect of skin diseases on quality of life in patients from different social and ethnic groups in Cape town, South Africa. Int J Dermatol 2000;39(11):826831. DOI:10.1046/j.1365-4362.2000.00073

3. Finlay AY, Khan GK. Dermatology Life Quality Index (DLQI) simple practical measure for routine clinical use. Clin Exp Dermato 1994;19(3):210-216. DOI:10.1111/j.1365-2230.1994.tb01167

4. Szepietowski JC, Reich A, Wesołowska-Szepietowska E, et al. Quality of life in patients suffering from seborrheic dermatitis: Influence of age, gender and education level. Mycoses Influence of age, gender and education level. Myc
2009;52(4):357-363. DOI:10.1111/j.1439-0507.2008.01624

5. Araya M, Kulthanan K, Jiamton S. Clinical characteristics and quality of life of seborrheic dermatitis patients in a tropical country Indian J Dermatol 2015;60(5):519. DOI:10.4103/0019-5154.164410 6. Peyri J, Lleonart M. Clinical and therapeutic profile and quality of life of patients with seborrhoeic dermatitis. Actas Dermosifiliog 2007;98(7):476-482. DOI:10.1016/S1578-2190(07)70491-2

7. Cedeno-Laurent F, Gómez-Flores M, Mendez N, et al. New insights into HIV-1 primary skin disorders. J Int AIDS Soc 2011;14:5. DOI:10.1186/1758-2652-14-5

S Afr Med J 2016;106(5):428

DOI:10.7196/SAMJ.2016v106i5.10551 